\title{
Experiences of overweight/obese adolescents in navigating their home food environment
}

\author{
Allison W Watts ${ }^{1, *}, \dagger$, Chris Y Lovato', Susan I Barr ${ }^{2}$, Rhona M Hanning ${ }^{3}$ and \\ Louise C Mâsse ${ }^{1}$ \\ ${ }^{1}$ School of Population and Public Health, University of British Columbia, Vancouver, BC, Canada: ${ }^{2}$ Food Nutrition \& \\ Health, University of British Columbia, Vancouver, BC, Canada: ${ }^{3}$ School of Public Health and Health Systems, \\ University of Waterloo, Waterloo, ON, Canada
}

Submitted 16 October 2014: Final revision received 16 February 2015: Accepted 20 February 2015: First published online 1 April 2015

\begin{abstract}
Objective: To explore perceived factors that impede or facilitate healthful eating within the home environment among overweight/obese adolescents.

Design: In the present qualitative photovoice study, participants were instructed to take photographs of things that made it easier or harder to make healthful food choices at home. Digital photographs were reviewed and semi-structured interviews were conducted to promote discussion of the photographs. Data were analysed using constant comparative analysis.

Setting: Vancouver, Canada, in 2012-2013.

Subjects: Twenty-two overweight/obese adolescents who completed a familybased lifestyle modification intervention.

Results: The mean age of participants was 14 (SD 1.9) years, $77 \%$ were female and their mean BMI $Z$-score was $2 \cdot 4$ (SD 0.6). Adolescents talked about six aspects of the home environment that influenced their eating habits (in order of frequency): home cooking, availability and accessibility of foods/beverages, parenting practices, family modelling, celebrations and screen use/studying. In general, homes with availability of less healthful foods, where family members also liked to eat less healthful foods and where healthier foods were less abundant or inaccessible were described as barriers to healthful eating. Special occasions and time spent studying or in front of the screen were also conducive to less healthful food choices. Home cooked meals supported adolescents in making healthier food choices, while specific parenting strategies such as encouragement and restriction were helpful for some adolescents.

Conclusions: Adolescents struggled to make healthful choices in their home environment, but highlighted parenting strategies that were supportive. Targeting the home food environment is important to enable healthier food choices among overweight/obese adolescents.
\end{abstract}

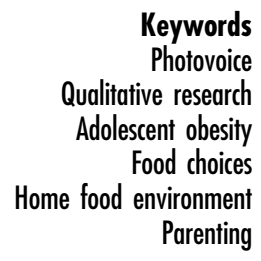

Keywords

research

Adolescent obesity

ood choices

Parenting
Rates of adolescent obesity have reached unprecedented levels in most developed countries ${ }^{(1,2)}$. Suboptimal diets have been implicated as contributing to this increase in obesity $^{(3)}$. During adolescence, the healthfulness of diets tends to decline ${ }^{(4-7)}$. For example, consumption of sugarsweetened beverages ${ }^{(4,7)}$, snacks ${ }^{(5)}$ and fast foods ${ }^{(5,6)}$ increases, while vegetable and fruit consumption ${ }^{(7)}$ decreases. Poor dietary quality in adolescence is of concern because dietary habits may carry forward into adulthood $^{(8)}$ and have long-term health implications,

† Present address: School of Public Health, University of Minnesota, 1300 South Second Street, Suite 300, Minneapolis, MN 55454, USA. including the development of obesity, heart disease, diabetes and certain cancers ${ }^{(9)}$.

Socio-ecological models highlight the role that environmental and interpersonal factors may play in influencing health behaviours ${ }^{(10)}$. As such, the home environment represents an important influence on the development of adolescent eating behaviours ${ }^{(11)}$. Specifically, parents can play a key role in shaping the home food environment by facilitating what foods are available and accessible, role modelling healthful or less healthful eating habits, establishing a style and/or practices through which food behaviours are navigated and by creating patterns that establish norms for eating within the family ${ }^{(12)}$. 
Across studies, associations between specific home environment factors and child and adolescent diet have been inconsistent and relatively few studies have been conducted with adolescents ${ }^{(13)}$, thus limiting our understanding of what influences adolescent eating behaviours in the home setting.

In adolescence, the role of the home environment likely plays a unique role. In North American culture, adolescence is a developmental period characterized by greater distancing from parents and increasing influence by peer groups $^{(14)}$. At the same time, parents continue to be a source of influence for many adolescents ${ }^{(14)}$ and a large proportion of their daily food intake occurs at home ${ }^{(5)}$. Although the home environment is recognized as an important target for changing lifestyle behaviours, current family-based interventions targeting adolescents have had only modest impact ${ }^{(15)}$.

To improve the success of behavioural interventions addressing adolescent obesity, there is a need to qualitatively explore how home environments impede or facilitate healthful dietary behaviours. Previous qualitative studies reveal a complex process underlying adolescent food choices (e.g. increased autonomy during adolescence) ${ }^{(16-21)}$ and highlight the need for greater knowledge regarding the unique aspects of the home setting influencing adolescents $^{(19)}$. For overweight/obese adolescents, the identification of familial factors that influence foodrelated behaviours may help to improve the success of adolescent obesity interventions ${ }^{(22)}$. Therefore, the purpose of the present study was to explore perceptions of barriers and facilitators to healthful eating within the home environment among a group of overweight/obese adolescents enrolled in a lifestyle modification intervention.

\section{Methods}

\section{Approach}

The present study employed phenomenological inquiry and photovoice methods to gain a deeper understanding of how home environments shape healthful dietary behaviours among overweight/obese adolescents. Phenomenological inquiry serves to uncover the meaning of individual experiences, commonly through individual interviews ${ }^{(23)}$. To complement this approach, aspects of photovoice methodology encourage participants to express their experiences visually through photographs ${ }^{(24)}$. Photovoice is a participatory and action-oriented research method that posits individual experiences can be interpreted through representations shared in pictures and words ${ }^{(25)}$. Combining phenomenology and photovoice approaches has been discussed in the literature as a means to enhance our understanding of a phenomenon by eliciting additional visual and narrative data ${ }^{(26)}$.
}

\section{Participants}

Participants were drawn from ninety-six parentadolescent pairs who completed an 8-month web-based lifestyle modification intervention ${ }^{(27)}$. The intervention's participants were recruited in Vancouver, British Columbia (BC), Canada through newspaper advertisements (62\%), letters sent to former participants of a hospital's endocrinology (13\%) and weight management clinics (15\%) and other sources (10\%). Eligibility criteria included being an adolescent aged $11-16$ years; a BMI $Z$-score greater than one standard deviation above the mean (overweight or obese according to the WHO age- and sex-matched growth charts); residing in the Vancouver area with no plans to move within the study period; grade 6 reading level; and English-speaking. Adolescents were excluded if they had co-morbidities that restricted physical activity or required medical attention, used medication affecting body weight, had type 1 diabetes or were participating in another weight-loss programme. The intervention involved participation of one parent and targeted nutrition, physical activity and sedentary behaviour through weekly lessons and tailored feedback on the website encouraging goal setting, self-monitoring and problem solving. Of the ninety-six adolescents who completed the intervention ( $57 \%$ female, $45 \%$ white and mean age of 13 years), twenty-three were ineligible for the current study because they were involved in another study and fifty-one declined to participate or could not be reached, leaving a total of twenty-two adolescents who participated in the current study.

\section{Protocol}

Pilot interviews were conducted with one adolescent and research staff to refine the protocol. Participants attended two one-on-one sessions with the primary author (a female doctoral student trained in nutrition and public health) at BC Children's Hospital Evaluation and Clinical Research Centre between September 2012 and April 2013. First, a session was conducted to deliver digital cameras, provide instructions, and explain the ethics, risk and importance of respecting privacy when using photography for research purposes. Each adolescent received five consent forms for potential subjects of their photographs. Adolescents were instructed to take five photographs of things that made it easier or harder to make healthful food and drink choices when they were in various settings (e.g. home, school and community). The limit of five photographs was thought to encourage greater reflection prior to taking photographs and reduce redundancy of a large number of photographs ${ }^{(26)}$. After a minimum of one week with the cameras (range: 1-12 weeks), a second session to review the photographs was held with each adolescent and individual semi-structured interviews were conducted. Adolescents also returned a log that included a description of each photograph including where and why each was taken. During the semi-structured interview, 
several probes encouraged in-depth discussion: 'Tell me about this photograph?'; 'Why did you take this photograph?'; 'What were you thinking/feeling when you took this photograph?'; 'Where was this taken?'; 'Does this happen a lot?'; 'Was there anything you wanted to take a picture of but couldn't or just didn't have time to?' Each adolescent and parent was asked for signed consent to use the photographs in research publications or presentations. Interviews ranged from 7 to $40 \mathrm{~min}$. Each adolescent was compensated \$CAN 10 for the first visit, \$CAN 25 for the second visit and entered into a draw to win a digital camera. Following the interview, field notes were taken, audio recordings were transcribed and each participant was mailed a copy of his/her photographic contribution to the study. To protect privacy, each participant was assigned a pseudonym for the storage, analysis and presentation of data. The current study is based on sixty-five photographs taken of home environments (65\% of all photos taken) as well as quotes from the interview transcripts that related to the home environment.

\section{Analysis}

Transcribed audio interviews, photographs and logs were analysed in Nvivo9 (2010) using directed constant comparative analysis ${ }^{(28)}$. Coding was conducted using a systematic and iterative process that was guided by a coding scheme based on previously developed socioecological models of adolescent food choices ${ }^{(10,11)}$. Analysis allowed for new codes to arise inductively, which permitted adolescents' phenomenological descriptions to be captured and interpreted ${ }^{(29)}$. A directed approach was chosen so that current theoretical models ${ }^{(10)}$ explaining the influence of the food environment could be tested, further described and potentially extended for this population.

First, data were coded into broader themes/categories from the original transcripts and then text belonging to each theme/category was examined to refine and expand each theme. Three of the co-authors were involved in analyses; the first three and seven additional transcripts (approximately every third transcript) were double coded ( $45 \%$ ). Each transcript was coded in its entirety and as each subsequent transcript was analysed, the previous coding was reviewed and revised where necessary. A coding document summarizing the themes and their definitions was continuously refined and updated when new codes emerged. During the second stage of coding, all quotes associated with each theme were examined and themes were refined by two co-authors, with a third co-author involved in discussing any uncertainties.

Several steps were taken to maximize the study's rigour $^{(30)}$. Rapport during face-to-face visits was built with participants prior to the interviews, interpretations were confirmed/disconfirmed during the interviews, a portion of analyses were completed by two co-authors independently (63\% agreement) with all interpretations of the data checked by co-authors, and visual and verbal interpretations were triangulated. In addition, results were verified with two participants and a detailed coding document and audit trail were maintained. Participants varied to some degree in terms of their gender, age and ethnicity/culture, which may help to increase the applicability of results to other groups of interest.

\section{Results}

Adolescents were, on average, 14 years old and were mostly female and from higher-income families (Table 1). The six primary themes identified were (in the order of frequency discussed by adolescents): (i) home cooking; (ii) availability and accessibility of foods/beverages; (iii) parenting practices; (iv) family modelling; (v) celebrations; and (vi) screen use and studying.

\section{Home cooking}

All but two adolescents talked about how home cooking impacted their food choices. Meals that were prepared at home were depicted as healthful, containing fruits and vegetables, and helped them control what they were eating. They demonstrated this by photographing their meals or individual food items that went into their meal (Fig. 1(a)). One adolescent talked about how she was able to make cookies in a more healthful way at home than if they were purchased. Another adolescent noted that her friend's parents buy frozen dinners, which she thought were less healthful. One boy mentioned that healthful meals also need to taste good, while another recognized that the preparation of home cooked meals from scratch involved foods that were not 'just microwavable' (Dan).

Many participants took pictures of and described routines that their families had around meals. One boy described a routine that was helpful, 'Every dinner that we have, we have a salad that goes alongside it' (Dan), while another described a routine that made it more difficult, 'Our Thursday tradition is a little sushi place right beside a pizza place and so [my parents will] go down and grab a couple slices of pizza and some sushi' (Scott).

\section{Availability and accessibility of foods/beverages}

The types of foods available at home were perceived as an important influence on food choices. Adolescents took pictures of the inside of their refrigerator or cupboards to illustrate the types of foods that were typically available. They struggled when the ratio of less healthful to healthful foods/drinks was high (Fig. 1(b)), such as when one boy stated:

'The food that we usually have... easily on hand and easy to get to is snacking stuff and stuff that's unhealthy, drinks that aren't healthy too.' (Scott) 
Table 1 Characteristics of the overweight/obese adolescent participants ( $n$ 22), Vancouver, Canada, 2012-2013

\begin{tabular}{|c|c|c|c|}
\hline & Mean & SD & Range \\
\hline Age (years) & $14 \cdot 3$ & 1.9 & $11-17$ \\
\hline BMI Z-score & $2 \cdot 2$ & 0.7 & $0.6-3.3$ \\
\hline Weight (kg) & 74.5 & $14 \cdot 2$ & $48 \cdot 0-102 \cdot 8$ \\
\hline \multirow[t]{2}{*}{ Height (m) } & 1.6 & 0.9 & $1 \cdot 4-1 \cdot 8$ \\
\hline & $n$ & $\%$ & \\
\hline Female sex & 17 & $77 \cdot 3$ & \\
\hline \multicolumn{4}{|l|}{ Parent ethnicity } \\
\hline White & 12 & 55.5 & \\
\hline Non-white & 10 & 45.5 & \\
\hline \multicolumn{4}{|l|}{ Annual household income (\$CAN) } \\
\hline$\leq 40000$ & 2 & $9 \cdot 1$ & \\
\hline$\overline{4} 0001-80000$ & 5 & $22 \cdot 7$ & \\
\hline $80001-120000$ & 4 & $18 \cdot 2$ & \\
\hline$>120000$ & 10 & $45 \cdot \overline{5}$ & \\
\hline Missing & 1 & 4.5 & \\
\hline \multicolumn{4}{|l|}{ Parent education } \\
\hline University degree & 13 & $59 \cdot 1$ & \\
\hline Trades certificate or diploma & 8 & $36 \cdot 4$ & \\
\hline$\leq$ High school & 1 & 4.5 & \\
\hline \multicolumn{4}{|l|}{ Parent marital status } \\
\hline Married/common-law & 17 & $77 \cdot 3$ & \\
\hline Divorced/single/widowed & 5 & $22 \cdot 7$ & \\
\hline
\end{tabular}

(a)

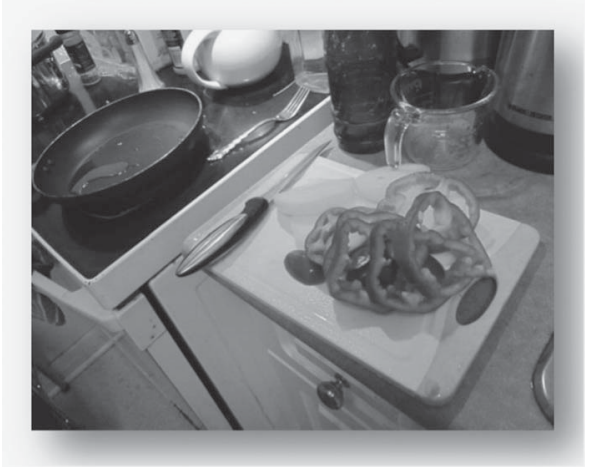

(c)

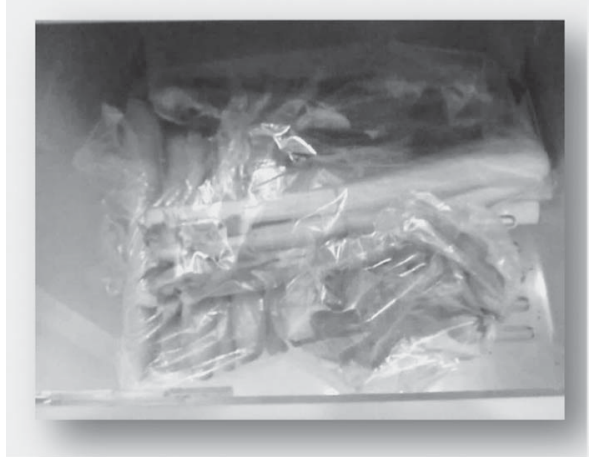

(b)

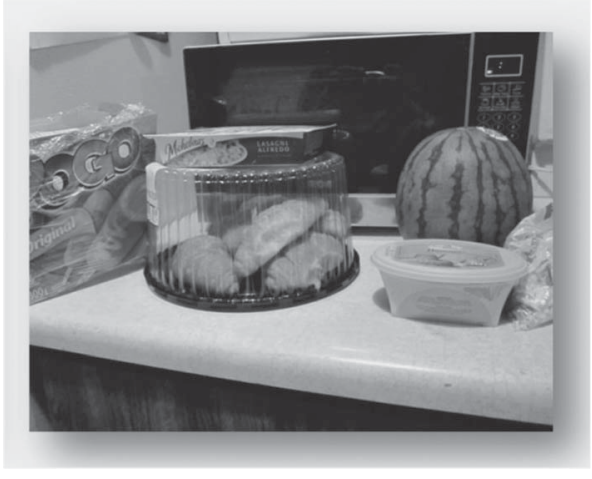

(d)

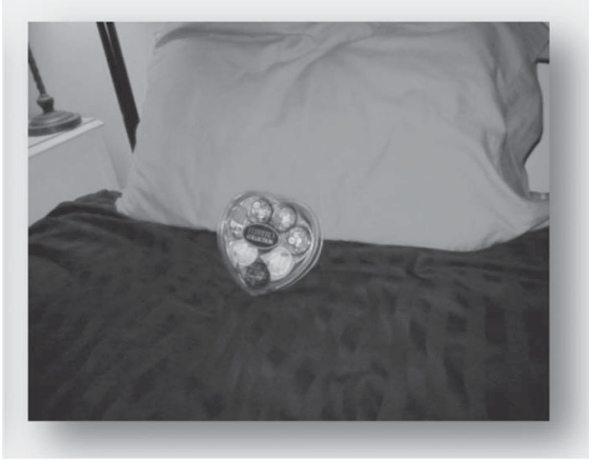

Fig. 1 Images captured by overweight/obese adolescent participants* when asked about barriers or facilitators to healthful eating in their home environment, Vancouver, Canada, 2012-2013. (a) Home cooking: 'This is a photo taken in my kitchen of me cooking dinner. When I cook, I cook with healthy ingredients and end with delicious results' (Dan). (b) Availability and accessibility of foods/ beverages: 'This is a photo taken at my dad's house of corn dogs, croissants and Michelina's ${ }^{\circledR}$ alfredo next to watermelon, hummus and coleslaw. It shows unhealthy food next to healthy food. It's representing that if there's a lot of unhealthy food and a lot of healthy food it would make me want to eat the unhealthy food' (Rob). (c) Availability and accessibility of foods/beverages: 'This is a photo taken at home of our fridge. These veggies are in our fridge all the time, and are often cut and ready to eat, as well. This makes it easier to eat healthy things at home and for lunches' (Lindsay). (d) Celebrations: 'This is a photo taken at home of Ferraro Rocher ${ }^{\circledR}$ chocolate. It's hard to eat well when you have holidays mostly devoted to eating' (Samantha). *Participant names are pseudonyms 
At the same time, having healthier alternatives on hand supported healthier eating, but wasn't always enough. For example, another boy described:

'We also have a shelf that's dedicated just for fruits and veggies which is always overflowing. [Interviewer: Do you like eating those?] Neh, the odd time, sometimes, yeah. Generally no.' (Finn)

In terms of food/beverage accessibility, adolescents said they were more likely to pick healthful foods and beverages if they were fast and easy to grab, such as precut vegetables, fruits ready to grab on the table, or hardboiled eggs in the refrigerator to take to school (Fig. 1(c)). Likewise, if less healthful foods were perceived as quick and easy to get, like frozen pizza or crackers, they were harder to resist. Less healthful foods that were also accessible were particularly hard to resist if an adolescent did not have a lot of time or depending on his/her physical/emotional state:

'If I'm feeling really unmotivated what I'm going to do is I'm going to go, I'm going to grab... a frozen pizza and throw it in the oven and... pour a can of pop or something and do something easy, lay around, watch TV.' (Scott)

Parents provided opportunities for their children to eat a healthful diet by making healthful foods more accessible. The most common examples included making fruits and vegetables more enticing and convenient (e.g. cutting them up, preparing servings for lunch, making them easy to spot) or making sweets less accessible (e.g. buying small packets as treats, cutting up fruit for dessert):

'Most of what's in there is relatively healthy on purpose. So when we look for something to eat, we'll get... vegetables or... fruits are on the table already. Like, as I said earlier... it's faster... than to try and find something that's not as healthy.' (Lindsay)

\section{Parenting practices}

Adolescents described barriers and facilitators to healthful eating when parents decided what foods were served at meals:

'If you're just having something for dinner and it's... healthy or not healthy... it's not like you can change it necessarily because if that's what... is made at home, then that's what you're going to eat.' (Emma)

It was helpful when parents asked their children for input when deciding what foods to purchase, 'She'll ask us which [fruits or vegetables] do we want 'cause then we'll eat them' (Lindsay), and when they prepared healthful family meals that everyone was eating. Adolescents felt it was harder to make good choices when their own requests or other family member's requests for less healthful foods were realized. For example, several participants described food availability or what they chose at home as not controlled by their parents and thus a barrier to healthful eating: 'my dad just lets me take whatever I want [from the grocery store]' (Suzy). A lack of parent control was also described as a barrier because adolescents were tempted by the presence of less healthful food at home. On the other hand, some adolescents described a rule or restriction that their parents imposed around eating that helped them to limit less healthful foods. For example, they described binging on certain foods when the food item was made available as a treat or when their parents were not at home or paying attention: having the house empty, I... automatically link that with, "I can grab some food, go quick"' (Rachel). Manipulative control by a parent (e.g. causing the adolescent to feel badly through comments or facial expressions) was described as a negative experience, but it was not clear how it impacted food choices:

'My mom will walk up and... sigh and make stupid faces at me... my parents they make it quite obvious that I'm not healthy, so it's sort of a negative way of pushing me to eat well.' (Samantha)

Participants described family support as helpful for making food choices. Several of them felt supported when their parents verbally encouraged them to eat healthful foods, but this also presented a challenge as one girl pointed out:

'My mom tries to help me make better choices but sometimes I don't listen to her... sometimes it's hard for me to talk... I don't like talking about stuff like that.' (Tina)

Siblings were also described as a source of verbal encouragement:

'If we're at the mall, [my sister will say] "what are you getting to eat?", and [I say] "you know I kind of want... Chinese food" and [my sister will say] "go to Subway, get a sandwich, you don't need that".' (Violet)

\section{Family modelling}

Adolescents described various types of household structures such as living with siblings, divorced parents (multiple households), grandparents and homestay students. They explained that their food choices were not made in isolation and were influenced by the preferences of others in the family:

'[My sister's] a really picky eater so my mom will usually cook something that she will like as well for the family. So, our nights kind of go like noodles, rice, noodles, rice, noodles, rice, noodles, rice, steak, noodles, rice, noodles, rice.' (Scott) 
Adolescents took photographs of their parents or siblings and talked frequently about the kinds of foods they ate. When parents or siblings liked to eat less healthful foods it made it harder for them to make healthy choices and increased their exposure to less healthful foods: 'When my brother buys a pack of chips it's sort of hard to resist. He always likes to eat unhealthy' (Suzy). Several participants described having siblings who were thin and could eat whatever they wanted: '[My sister] kind of makes it hard I guess because she can eat anything and not gain like a pound. Like, I want to eat what she eats' (Tina). Thin siblings were allowed to eat less healthful foods without any perceived consequences, resulting in jealousy and temptation for overweight/obese adolescents.

In addition to the increased temptation, adolescents talked about their sibling as someone who they could eat less healthful foods with or as someone they needed to compete with in order to get a share of less healthful food. For example, one girl stated:

'I know I want to get to it before [my brother] does 'cause I know I won't get any if he's there first. So it's kind of, "overdo it to the max" because I know he will too.' (Rachel)

In contrast, it helped adolescents when their parents or siblings modelled healthful eating because they felt like they were eating healthfully together: '[My dad] just eats healthy with me' (Jenny). More health-focused siblings were also described as motivating. Also, it is a challenge when participants were exposed to healthful modelling in one household but not the other. For example, one boy talked about having healthful food available at his mom's house, but lots of 'yummy' foods available at his dad's house. He observed that: 'My mom's into health and all that, but my dad isn't' (Finn).

\section{Celebrations}

Holidays and celebrations were portrayed as particularly challenging because there was an excessive amount of less healthful food available and there was a social expectation to eat less healthful food. Photographs illustrated the type of food that they received, or consumed, during a particular holiday (Fig. 1(d)). Participants talked about the norms around particular holidays, for example at Halloween: 'It's not like [you have to eat treats at Halloween] but it's kind of, if it only happens once a year, might as well... enjoy it' (Rachel). Eating on special occasions was also related to saving face: 'Like this time we were going to have fruit but then [our company] brought a cake and we didn't want to be rude. So we ate it' (Lily). Interestingly, almost all major holidays were photographed (Halloween, Thanksgiving, Christmas, Valentine's Day and Easter) and all adolescents who discussed the holidays highlighted them as barriers to healthful eating.

\section{Screen use and studying}

Adolescents took photographs of computers, the television or school books and described eating less healthful snacks when engaging in these activities, as one boy described:

'I actually eat a lot more when I'm using my computer than I do [otherwise]. [I usually eat] stuff that I probably shouldn't, like small snacks and stuff that tend to build up... like crackers or chips.' (Scott)

He further elaborated:

'A lot of friends and myself can get really stressed out with our homework and when you're stressed it's like comfort food is probably not the healthiest stuff right, but it's what you want to eat.' (Scott)

Adolescents talked about 'mindless eating' and felt that choosing less healthful foods occurred mostly out of boredom and habit but also because they were hungry after school, and while studying they are stressed, have limited time or want to procrastinate. Although only a small number of adolescents talked about screen time as a barrier to healthful eating, it was highlighted by those who did discuss it. In addition, only older participants (14-17 years old) talked about this theme.

\section{Discussion}

The present study qualitatively explored overweight/obese adolescents' perceptions of barriers and facilitators to healthful eating in the home environment. To our knowledge, it is the first study to use photovoice to examine home food environments among overweight/obese adolescents. Detailed, in-depth accounts from the unique perspectives of overweight/obese adolescents are needed to improve the success of behavioural interventions targeting this group. Our findings highlight that the home food environment can play an important role in determining the types of foods and drinks that adolescents consume. Many of the themes that emerged from the study align with previous research and socio-ecological theory ${ }^{(10)}$ that suggest multiple aspects of the home environment and interpersonal factors within the home have an impact on food choices. In general, homes where less healthful foods were available, healthier foods were inaccessible and family members ate less healthful foods were perceived as barriers to healthful eating. Special occasions and time spent studying or in front of screens were also barriers to healthful eating, while home cooked meals supported adolescents in making healthier food choices. Overall, in the home setting, a mix of individual, social and physical factors likely need to be targeted by dietary behaviour change interventions. These interventions should go beyond educating overweight/obese adolescents about these influences by targeting families, social interactions and the home environment directly. 
As in previous studies, parents' own behaviours and the family routines that parents help to create were described as important to adolescent food choices. There is a large body of research examining how parenting practices, including rules and feeding styles, impact children's dietary intake ${ }^{(12,31)}$, but findings in this area have been mixed, suggest modest effect sizes and are primarily obtained from studies of younger children ${ }^{(32)}$. Adolescents in the present study did identify parent encouragement, restriction/rules, child autonomy, indulgence/permissiveness and parent modelling of healthful and less healthful foods/ beverages as influences on food choice. Findings also suggested that restrictions helped to control eating for some adolescents, but not others. High levels of parent restriction or control over desirable foods may lead to increased desire and intake of those foods when they become available ${ }^{(16,33)}$. Parent restriction and control over certain foods may, therefore, be detrimental to some overweight/obese adolescents.

Parent modelling of desired eating behaviours has been reported in the literature as a more consistent and successful method to improve a child's diet than attempts at parental control ${ }^{(34)}$. However, many adolescents in the present study described parents, as well as siblings, who modelled less healthful eating, suggesting that healthful modelling remains a challenge for families seeking paediatric weight management ${ }^{(35)}$. In particular, the descriptions provided by adolescents in the present study suggest that it would be beneficial for the whole family to model healthful eating. Despite the potential for parents to promote healthful eating among their adolescent children, the growing independence and autonomy that occurs during adolescent development makes the influence of parenting strategies particularly difficult to establish, as was previously described in interviews with parents of overweight/obese adolescents ${ }^{(35)}$.

The potential for home cooked family meals to support healthful eating has been well documented ${ }^{(36-38)}$. The adolescents in the present study described the quality of the food that was served, involvement in food preparation, the control that parents had over meals, and the preferences of other family members as mechanisms for how family meals impacted their choices. In some families, adolescents have little involvement in meal preparation $^{(16)}$, yet adolescence may be an ideal time to foster this behaviour. Involvement in home meal preparation provides an opportunity for adolescents to exert autonomy and independence ${ }^{(39)}$. Studies have reported that greater involvement in meal preparation is associated with adolescent food preferences ${ }^{(40)}$, self-efficacy ${ }^{(40)}$ and better dietary quality ${ }^{(41)}$. To improve healthful eating, parents of overweight/obese adolescents may need to prioritize home cooked meals and encourage adolescents to take part in cooking healthy meals.

It may also be important for families with overweight/ obese adolescents to provide as many healthful foods as possible while ensuring limited or no availability of less healthful foods in the home. This finding is also supported by previous studies that report adolescents perceive availability and accessibility of healthful and less healthful food/beverages at home as influencing their food choice ${ }^{(17,18)}$. Home availability has also been found to promote healthful changes in fruit and vegetable ${ }^{(42)}$, energy-dense snack ${ }^{(42)}$ and sugary drink ${ }^{(43)}$ consumption, thus is applicable to behaviour change programmes. Availability of less healthful foods may be of particular concern during holidays/celebrations and families may want to consider de-emphasizing treats over the holidays. An alternative might be to make family activities a focus of special occasions, but further research should assess the acceptance of such alternatives. In addition, no previous qualitative study has reported that holidays/celebrations were barriers to healthful eating; however, social pressures to eat less healthful foods and using less healthful foods as treats have been described by adolescents in previous studies $^{(16)}$. Interventions that educate and support parents in making healthier purchasing decisions in general and during holidays are warranted, but will also need to consider a family's financial constraints. Such educationbased interventions have been successful at increasing perceptions of healthful food affordability among mothers of low socio-economic status in Australia ${ }^{(44)}$, which may lead to changes in food purchasing.

Finally, a small number of adolescents identified screen use and studying as a barrier to healthful eating, which has been linked with the consumption of less healthful foods/ beverages in previous studies ${ }^{(42,45)}$. Participants thought this was related to boredom, lack of awareness, hunger, stress and social reasons, while previous studies have identified distraction, lack of awareness and advertising as factors contributing to overconsumption while watching television ${ }^{(46,47)}$. A recent longitudinal study reported an association between screen time and BMI that was stronger at higher BMI levels, suggesting screen time may be a more important influence on weight-related behaviours such as eating habits for overweight/obese adolescents ${ }^{(48)}$. Similar to screen time, studying was related to less healthful eating behaviours in the current study and has not been documented previously. The only age-group difference identified in the present study was that only older adolescents (14-17 years) mentioned screen time and studying as a barrier to healthful eating. This was surprising, but may reflect the increasing prevalence of screen use and studying as children age ${ }^{(49)}$.

\section{Conclusions}

The overweight/obese adolescent participants of the present study perceived many barriers in their homes to achieving healthful diets. The study participants had just completed a web-based lifestyle behaviour change 
programme and the general findings presented here may be applicable to similar adolescents participating in obesity treatment programmes. Although participants were exposed to the same intervention curriculum about healthy eating, differences in nutrition knowledge may have influenced their perceptions. In addition, the age and developmental level of participants could have influenced what they chose to share. The results support broader consideration of the home environment in family-based obesity treatment programmes; however, further research is needed to identify the best mix of factors within the home environment that support healthy food choices among overweight/obese adolescents. Identifying barriers that families face in creating more supportive home food environments would also be valuable for development of intervention strategies.

In addition to parent involvement in interventions, lifestyle behaviour interventions that involve overweight/ obese adolescents should consider the entire family and target changes to the home environment that support healthier behaviours. Creating a supportive home environment for healthful eating requires consideration of multiple aspects of the home food environment (e.g. availability, parenting, siblings, modelling), as well as the potential influence of a second household (e.g. divorced parents). These broader considerations are critical as interventions that focus solely on the adolescent (e.g. education and tools to increase self-efficacy and motivation) will not be sustained in an environment that has competing unhealthy opportunities. Food environments beyond the home, such as schools and neighbourhoods, likely also contribute to the quality of adolescent diets and future research needs to tease apart the role that each of these environments plays on food choices.

\section{Acknowledgements}

Financial support: This study was funded by the Canadian Institutes of Health Research (CIHR) Institute of Nutrition, Metabolism and Diabetes and the Health Research Foundation agreement number 00789-000. Support funding was received from a CIHR Doctoral Research Award in partnership with the Danone Institute of Canada; a CIHR fellowship in population interventions for chronic disease prevention in partnership with the Heart and Stroke Foundation of Canada; and by the Child and Family Research Institute. The funders had no role in the design, analysis or writing of this article. Conflict of interest: None. Authorship: A.W.W. formulated the research question, designed the study, collected the data, conducted the qualitative analyses, interpreted the results and prepared the manuscript. C.Y.L., S.I.B., R.M.H. and L.C.M. participated in study design and data interpretation, and critically reviewed the manuscript. C.Y.L. and L.C.M. also participated in data analysis. Ethics of human subject participation: This study was conducted according to the guidelines laid down in the Declaration of Helsinki and all procedures involving human subjects/patients were approved by the Behavioural Research Ethics Board at the University of British Columbia and the Office of Research Ethics at the University of Waterloo. Written informed consent was obtained from all subjects/patients.

\section{References}

1. World Health Organization (2011) Childhood overweight and obesity. http://www.who.int/dietphysicalactivity/ childhood/en/ (accessed November 2011).

2. Roberts KC, Shields M, de Groh M et al. (2012) Overweight and obesity in children and adolescents: results from the 2009 to 2011 Canadian Health Measures Survey. Health Rep 23, 37-41.

3. Linde J \& Jeffery R (2010) Evolving environmental factors in the obesity epidemic. In Obesity Epidemiology: From Aetiology to Public Health, 2nd ed., pp. 119-135 [D Crawford, RW Jeffery, K Ball et al., editors]. New York: Oxford University Press.

4. Garriguet D (2008) Beverage consumption of children and teens. Health Rep 19, 1-7.

5. Garriguet D (2007) Canadians' eating habits. Health Rep 18, $17-32$.

6. Laska MN, Murray DM, Lytle LA et al. (2012) Longitudinal associations between key dietary behaviors and weight gain over time: transitions through the adolescent years. Obesity (Silver Spring) 20, 118-125.

7. Lytle LA, Seifert S, Greenstein J et al. (2000) How do children's eating patterns and food choices change over time? Results from a cohort study. Am J Health Promot 14, 222-228.

8. Patterson E, Wärnberg J, Kearney J et al. (2009) The tracking of dietary intakes of children and adolescents in Sweden over six years: the European Youth Heart Study. Int J Behav Nutr Phys Act 6, 91.

9. Reilly J \& Kelly J (2011) Long term impact of overweight and obesity. Int J Obes (Lond) 35, 891-898.

10. Story M, Kaphingst KM, Robinson-O'Brien R et al. (2008) Creating healthy food and eating environments: policy and environmental approaches. Annu Rev Public Health 29, 253-272.

11. Rosenkranz RR \& Dzewaltowski DA (2008) Model of the home food environment pertaining to childhood obesity. Nutr Rev 66, 123-140.

12. Birch LL \& Davison KK (2001) Family environmental factors influencing the developing behavioral controls of food intake and childhood overweight. Pediatr Clin North Am 48, 893-907.

13. De Vet E, de Ridder DTD \& de Wit JBF (2011) Environmental correlates of physical activity and dietary behaviours among young people: a systematic review of reviews. Obes Rev 12, e130-e142.

14. Nurmi RM (2004) Socialization and self-development. In Handbook of Adolescent Psychology, 2nd ed., pp. 85-124 [RM Lerner and M Steinberg, editors]. New York: John Wiley \& Sons.

15. Kelly SA \& Melnyk BM (2008) Systematic review of multicomponent interventions with overweight middle adolescents: implications for clinical practice and research. Worldviews Evid Based Nurs 5, 113-135.

16. Stevenson C, Doherty G, Barnett J et al. (2007) Adolescents' views of food and eating: identifying barriers to healthy eating. $J$ Adolesc 30, 417-434. 
17. Neumark-Sztainer D, Story M, Perry C et al. (1999) Factors influencing food choices of adolescents: findings from focus-group discussions with adolescents. J Am Diet Assoc 99, 929-937.

18. Fitzgerald A, Heary C, Nixon E et al. (2010) Factors influencing the food choices of Irish children and adolescents: a qualitative investigation. Health Promot Int 25, 289-298.

19. Holsten JE, Deatrick JA, Kumanyika S et al. (2012) Children's food choice process in the home environment. A qualitative descriptive study. Appetite 58, 64-73.

20. St. George SM \& Wilson DK (2012) A qualitative study for understanding family and peer influences on obesity-related health behaviors in low-income African-American adolescents. Child Obes 8, 466-476.

21. O'Dea JA (2003) Why do kids eat healthful food? Perceived benefits of and barriers to healthful eating and physical activity among children and adolescents. J Am Diet Assoc 103, 497-501.

22. Skelton JA, Buehler C, Irby MB et al. (2012) Where are family theories in family-based obesity treatment?: conceptualizing the study of families in pediatric weight management. Int J Obes (Lond) 36, 891-900.

23. Lopez KA \& Willis DG (2004) Descriptive versus interpretive phenomenology: their contributions to nursing knowledge. Qual Health Res 14, 726-735.

24. Martin N, Garcia AC \& Leipert B (2010) Photovoice and its potential use in nutrition and dietetic research. Can J Diet Pract Res 71, 93-97.

25. Wang C \& Burris MA (1997) Photovoice: concept, methodology, and use for participatory needs assessment. Health Educ Behav 24, 369-387.

26. Plunkett R, Leipert BD \& Ray SL (2012) Unspoken phenomena: using the photovoice method to enrich phenomenological inquiry. Nurs Inq 20, 156-164.

27. Mâsse LC, Watts AW, Barr SI et al. (2014) Individual and household predictors of adolescents' adherence to a webbased intervention. Ann Behav Med (Epublication ahead of print version).

28. Hewitt-Taylor J (2001) Use of constant comparative analysis in qualitative research. Nurs Stand 15, 39-42.

29. Hsieh H-F \& Shannon SE (2005) Three approaches to qualitative content analysis. Qual Health Res 15, 1277-1288.

30. Lincoln Y \& Guba E (1985) Naturalistic Inquiry. Newbury Park, CA: Sage Publications.

31. Gerards SMPL, Sleddens EFC, Dagnelie PC et al. (2011) Interventions addressing general parenting to prevent or treat childhood obesity. Int J Pediatr Obes 6, e28-e45.

32. Kremers S, Sleddens E, Gerards S et al. (2013) General and food-specific parenting: measures and interplay. Child Obes 9, Suppl., S22-S31.

33. Birch LL \& Fisher JO (2000) Mothers' child-feeding practices influence daughters' eating and weight. Am J Clin Nutr 71, 1054-1061.
34. Brown R \& Ogden J (2004) Children's eating attitudes and behaviour: a study of the modelling and control theories of parental influence. Health Educ Res 19, 261-271.

35. Boutelle KN, Feldman S \& Neumark-Sztainer D (2012) Parenting an overweight or obese teen: issues and advice from parents. J Nutr Educ Behav 44, 500-506.

36. Burgess-Champoux TL, Larson N, Neumark-Sztainer D et al. (2009) Are family meal patterns associated with overall diet quality during the transition from early to middle adolescence? J Nutr Educ Behav 41, 79-86.

37. Hammons AJ \& Fiese BH (2011) Is frequency of shared family meals related to the nutritional health of children and adolescents? Pediatrics 127, e1565-e1574.

38. Larson NI, Neumark-Sztainer D, Hannan PJ et al. (2007) Family meals during adolescence are associated with higher diet quality and healthful meal patterns during young adulthood. J Am Diet Assoc 107, 1502-1510.

39. Simmons D \& Chapman GE (2012) The significance of home cooking within families. Br Food J 114, 1184-1195.

40. Chu YL, Farmer A, Fung C et al. (2013) Involvement in home meal preparation is associated with food preference and self-efficacy among Canadian children. Public Health Nutr 16, 108-112.

41. Larson NI, Story M, Eisenberg ME et al. (2006) Food preparation and purchasing roles among adolescents: associations with sociodemographic characteristics and diet quality. J Am Diet Assoc 106, 211-218.

42. Pearson N, Ball K \& Crawford D (2011) Predictors of changes in adolescents' consumption of fruits, vegetables and energy-dense snacks. Br J Nutr 105, 795-803.

43. Ezendam NPM, Evans AE, Stigler MH et al. (2010) Cognitive and home environmental predictors of change in sugarsweetened beverage consumption among adolescents. Br J Nutr 103, 768-774.

44. Williams LK, Abbott G, Thornton LE et al. (2014) Improving perceptions of healthy food affordability: results from a pilot intervention. Int J Behav Nutr Phys Act 11, 1-5.

45. Ciccone J, Woodruff SJ, Fryer K et al. (2013) Associations among evening snacking, screen time, weight status, and overall diet quality in young adolescents. Appl Physiol Nutr Metab 38, 789-794.

46. Temple JL, Giacomelli AM, Kent KM et al. (2007) Television watching increases motivated responding for food and energy intake in children. Am J Clin Nutr 85, 355-361.

47. Dennison BA \& Edmunds LS (2008) The role of television in childhood obesity. Prog Pediatr Cardiol 25, 191-197.

48. Mitchell JA, Rodriguez D, Schmitz KH et al. (2013) Greater screen time is associated with adolescent obesity: a longitudinal study of the BMI distribution from ages 14 to 18 . Obesity (Silver Spring) 21, 572-575.

49. Atkin AJ, Corder K \& van Sluijs EM (2013) Bedroom media, sedentary time and screen-time in children: a longitudinal analysis. Int J Behav Nutr Phys Act 10, 137. 